\title{
Experimental Investigations on Electroless Deposition of Copper on Basalt Fibers
}

\author{
S. Ezhil Vannan \\ Department of Mechanical Engineering, HKBK College of Engineering, Bangalore, India \\ Email: ezhilsil@yahoo.co.in
}

Received 2 June 2015; accepted 14 June 2015; published 17 June 2015

Copyright (C) 2015 by author and Scientific Research Publishing Inc. This work is licensed under the Creative Commons Attribution International License (CC BY). http://creativecommons.org/licenses/by/4.0/

(c) (7) Open Access

\begin{abstract}
In this work, an electroless method of coating copper on the basalt short fibers using copper sulphate solution is described. In order to avoid any interfacial reactions in the basalt fiber reinforced metal matrix composites, the basalt fibers were coated with copper. The effects of the time of sensitization, activation, metallization, $\mathrm{PdCl}_{2}$ concentration, $\mathrm{pH}$ and temperature bath on the extent of copper coating on basalt fiber are reported. The conditions used for electroless coating were optimized to obtain a uniform and continuous layer of copper. Using this method, it is possible to deposit up to about 25 wt\% copper on the basalt fiber. The resultant composite fiber was characterized by scanning electron microscopy (SEM)/energy-dispersive X-ray (EDX) during and after the coating process. The effects of the thickness of copper coating on surface condition and also the tensile strength of the basalt fibers have been investigated. The study of surface condition of the coated basalt fibers by SEM showed that the copper coating at the thickness of about $0.2 \mu \mathrm{m}$ had the best continuity on the basalt fibers. The results of tensile tests of basalt fibers coated with different thickness of copper showed that increasing the thickness of coating layer decreased the overall strength of fibers.
\end{abstract}

\section{Keywords}

Basalt Fibers, Copper Coating, Electroless Method, Surface Condition, Tensile Strength

\section{Introduction}

Fiber reinforced metal matrix composites developed in the last few decades are leading to remarkable improvements in industries, due to its excellent mechanical and chemical properties and high cost performance [1]. Aerospace, automotive and other industries are always striving to find newer and better reinforcing materials to manufacture new or improved products for new applications [2]. Many natural and synthetic fibers have been 
used as the reinforcement for Metal Matrix Composites [MMCs]. Ideally, any fiber should be lightweight, chemically and thermally stable, possessing good mechanical properties and cheap. Actually, no real material reveals these properties altogether. Recently, attention has been devoted to Basalt Fibers (BF), a sustainable alternative for fiber reinforcement, whose primary advantage consists of its low cost, good resistance to acids and solvents, good thermal stability, higher modulus, and strength and better electrical insulating properties [3]. Basalt fiber is a natural material which is produced from igneous rock called basalt and gives a great strength relative to weight [4]. Various researchers have shown that basalt fiber has versatile material properties [5]-[7].

The nature of interface plays a most vital role in the overall performance of a composite material. Improper wetting and chemical reaction occurring between the dispersoid surface and matrix at the interface can degrade the mechanical properties of the composites [8]. To solve these problems, many researchers [9]-[11] have used technique of coating the reinforcement. Metals like copper, silver, nickel, tantalum, cobalt, ceramics like titanium boride and born carbide have been used to coat fibers [12]. An electroless copper coating of the reinforcement approach, which is simple, low-cost and easy to use process has been successfully applied to prevent undesirable interfacial reactions and promote the wettability through increased overall surface energy of the reinforcement [13]-[16]. Many researchers used addition of wetting agents and few used surface modification by electroless deposition of metal elements for improving the wettability of the reinforcement [17].

In this research, an attempt is made to modify the surface of the reinforcement by coating with copper using electroless method and to study the influence of electroless coating parameters such as effects of sensitization time (A), activation time, metallization time, $\mathrm{PdCl}_{2}$ concentration, $\mathrm{pH}$ and temperature bath on the extent of copper on coating morphology of basalt fiber.

\section{Experimental Procedure}

\subsection{Materials and Methods}

Basalt fibers used in this study were supplied by Mukhtha Giri industrial corporation, Mumbai in the form of Continuous Basalt Fibers (CBF). These are natural fibers produce by crushing the volcanic rocks and then melting them between temperatures $1300^{\circ} \mathrm{C}-1700^{\circ} \mathrm{C}$ to produced into fine fibers. They have average diameter of 6 $\mu \mathrm{m}$, an elastic modulus of $90 \mathrm{GPa}$, and a yield stress of $4500 \mathrm{MPa}$. The continuous fibers were cut down into short fiber to length about $0.5 \mathrm{~mm}$, although the mechanical method used gives wide length distribution between 50 and $700 \mu \mathrm{m}$. The chemical composition of basalt fiber is shown in Table 1.

\subsection{Electroless Fiber Coating with Copper}

The cut short basalt fibers were coated with copper using electroless method. The process of coating onto the fibers relies on a sequence of preheating, sensitizing, activation and metallization, with important cleaning, rinsing, and drying stages also being included. The conditions used are detailed in Table 2. Table 2 summarizes the best working procedure used, which is based on improving different solutions used by some authors [18]-[22].

The complete process of coating starts with the organic sizing and finish treatment of fibers in a muffle furnace for $10 \mathrm{~min}$ at $500^{\circ} \mathrm{C}$ to eliminate the pyrolytic coatings around as - received fibers. After cleaning the fibers in an air furnace for $10 \mathrm{~min}$ at $500^{\circ} \mathrm{C}$, they were sensitized for $15 \mathrm{~min}$ under continuous stirring. Afterwards, fibers were filtered and cleaned with distilled water. In order to get catalytic surfaces, the fibers were activated under ultrasonic agitation. The heat cleaned fibers were first treated with glacial acetic acid to activate the surface, and then again activated using stannous chloride $\left(12 \mathrm{~g} / \mathrm{l} \mathrm{SnCl}_{2}-2 \mathrm{H}_{2} \mathrm{O}\right)$ and $40 \mathrm{ml} / \mathrm{l}$ of concentrated hydrochloric acid they were sensitized for different times under continuous stirring. Afterwards, fibers are filtered and cleaned with distilled water. In order to have catalytic surfaces, the sensitized fibers were exposed to an aqueous solution containing palladium chloride $\left(0.2 \mathrm{~g} / 1 \mathrm{PdCl}_{2}\right)$ and $(2.5 \mathrm{~m} / 1 \mathrm{HCl})$ under ultrasonic agitation. This process, called activation, produces the formation of Pd sites on the fiber surface which allow the subsequent metallization with copper.

Metallization is produced by immersion of activated fibers into a solution containing $\mathrm{CuSO}_{4}-5 \mathrm{H}_{2} \mathrm{O}$ as metal ion sources also held under agitation. Different metallization conditions have been tested, $\mathrm{pH}$ ( 12 \& 13), time ( 2 min to $20 \mathrm{~min})$ and temperature $\left(40^{\circ} \mathrm{C} \& 50^{\circ} \mathrm{C}\right)$, and continuous and crystalline coatings with homogeneous thickness have been obtained. The reactive volume used assures that the concentration of the diluted copper can 
Table 1. Chemical composition of short basalt fiber.

\begin{tabular}{cccccccccc}
\hline Element & $\mathrm{SiO}_{2}$ & $\mathrm{Al}_{2} \mathrm{O}_{3}$ & $\mathrm{Fe}_{2} \mathrm{O}_{3}$ & $\mathrm{MgO}$ & $\mathrm{CaO}$ & $\mathrm{Na}_{2} \mathrm{O}$ & $\mathrm{K}_{2} \mathrm{O}$ & $\mathrm{TiO}_{2}$ & $\mathrm{MnO}$ \\
\hline$\%$ & 69.51 & 14.18 & 3.92 & 2.41 & 5.62 & 2.74 & 1.01 & 0.55 & 0.04 \\
\hline
\end{tabular}

Table 2. Chemical compositions.

\begin{tabular}{cc}
\hline Stage and conditions & Concentration of chemicals \\
\hline Sesitization & $12 \mathrm{~g} / 1 \mathrm{SnCl}_{2}-2 \mathrm{H}_{2} \mathrm{O}$ \\
$5 \mathrm{~min}, 10 \mathrm{~min} \& 15$ min at room temperature & $40 \mathrm{ml} / 1 \mathrm{HCl}$ \\
Activation & $0.2 \mathrm{~g} / 1 \mathrm{PdCl}_{2}$ \\
$5 \mathrm{~min}, 10$ min \& 15 min at room temperature & $2.5 \mathrm{~m} / 1 \mathrm{HCl}$ \\
Metallization & $10 \mathrm{~g} / 1 \mathrm{CuSO}_{4}-5 \mathrm{H}_{2} \mathrm{O}$ \\
Multiple conditions tested & $45 \mathrm{~g} / 1 \mathrm{EDTA}$ \\
$40^{\circ} \mathrm{C}$ and $50^{\circ} \mathrm{C}$ & $20 \mathrm{~g} / 1 \mathrm{NaCOOH}$ \\
$\mathrm{pH} 12$ and $\mathrm{pH} 13$ & $16 \mathrm{ml} / 1 \mathrm{HCHO} 36 \%$ \\
2 min $-20 \mathrm{~min}$ & $\mathrm{NaOH}$ for adjusting pH \\
\hline
\end{tabular}

be considered constant during the deposition. The coatings obtained at different metallization temperature, time and $\mathrm{pH}$ values were studied by SEM and the thickness of the copper layer was determined in transversal cross section.

\section{Results and Discussions}

The various factors affecting the extent of copper coating on basalt fiber are described below.

\subsection{Effect of Time of Sensitization}

The effect of time of sensitization on the weight percent of copper deposited is shown in Figure 1.

Apparently, as the time for sensitization increases, the surface becomes more and more suitable to receive a coating. However, after about 15 minutes of sensitization, there appears to be no significant increase in the amount of copper deposited with further increase in sensitization time.

\subsection{Effect of Time of Activation}

The effect of time of activation on the weight percentage of copper deposited is shown in Figure 2. Apparently, as the time for activation increases, the surface becomes more and more suitable to receive a coating. However, after about 15 minutes of activation, there appears to be no significant increase in the amount of copper deposited with further increase in activation time.

\subsection{Effect of Concentration of $\mathrm{PdCl}_{2}$}

The effect of $\mathrm{PdCl}_{2}$ concentration on the weight percent of copper deposited is shown in Figure 3. It can be seen that the changes in weight percent of copper deposited with a change in $\mathrm{PdCl}_{2}$ concentration from 0.1 to $0.25 \mathrm{~g} / 1$ of $\mathrm{PdCl}_{2}$ is from 27 to 37 .

\subsection{Effect of Stirring Time in Electroless Bath}

Figure 4 shows that as the stirring time of basalt fibers in the electroless bath increases, the percent of copper deposited on the basalt fibers also increases up to a stirring time of about $30 \mathrm{~min}$. The coating reaction starts as soon as the basalt short fibers activated by $\mathrm{PdCl}_{2}$ are dispersed in the coating solution. Palladium metal at the surface of the basalt fiber acts as a catalyst. After the start of the coating reaction it proceeds autocatalytically. After putting the activated basalt fiber in the electroless bath, the bath should be stirred continuously to obtain a uniform coating of copper on the basalt fibers. The colour of the electroless solution changes progressively as 


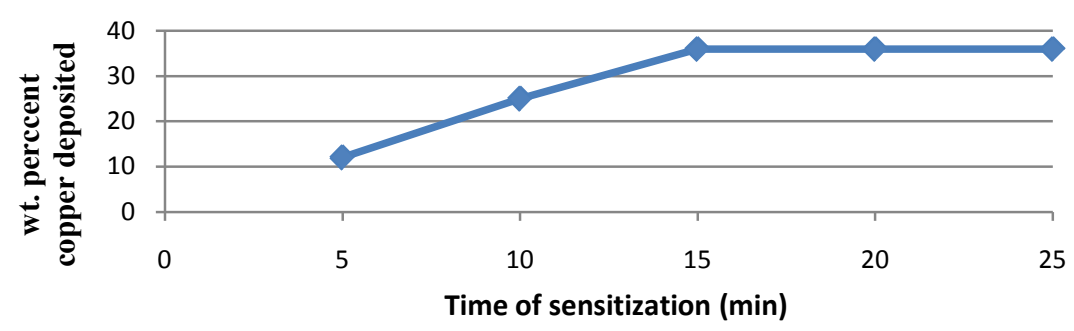

Figure 1. Effect of time of sensitization on weight percent of copper deposited.

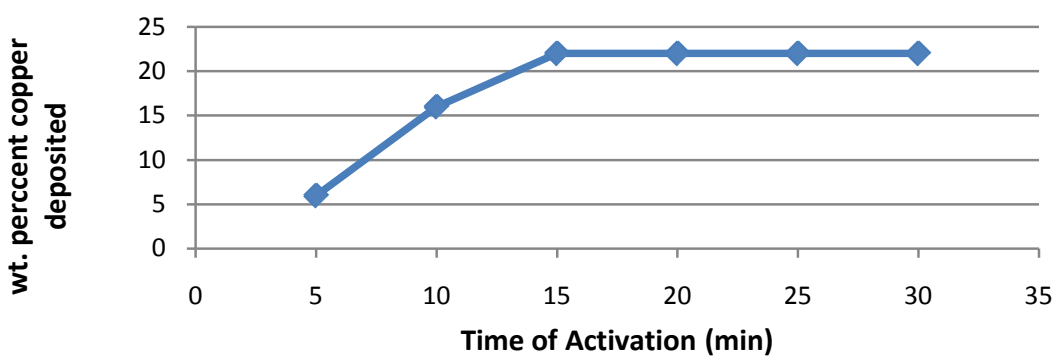

Figure 2. Effect of time of activation on weight percent of copper deposited.

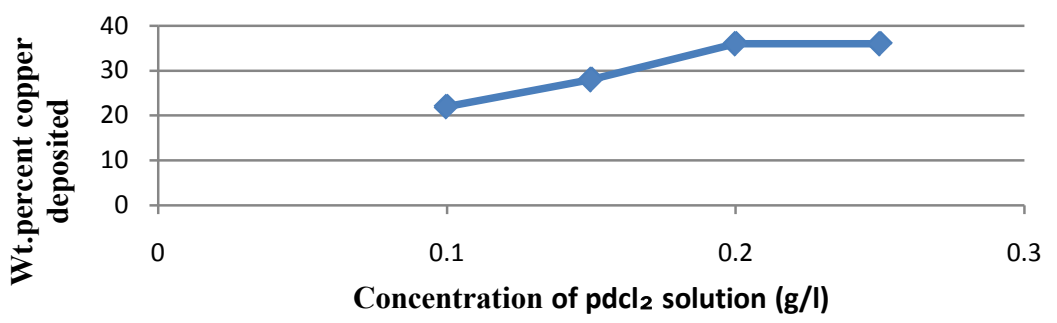

Figure 3. Effect of time of concentration of $\mathrm{PdCl}_{2}$ on weight percent of copper deposited.

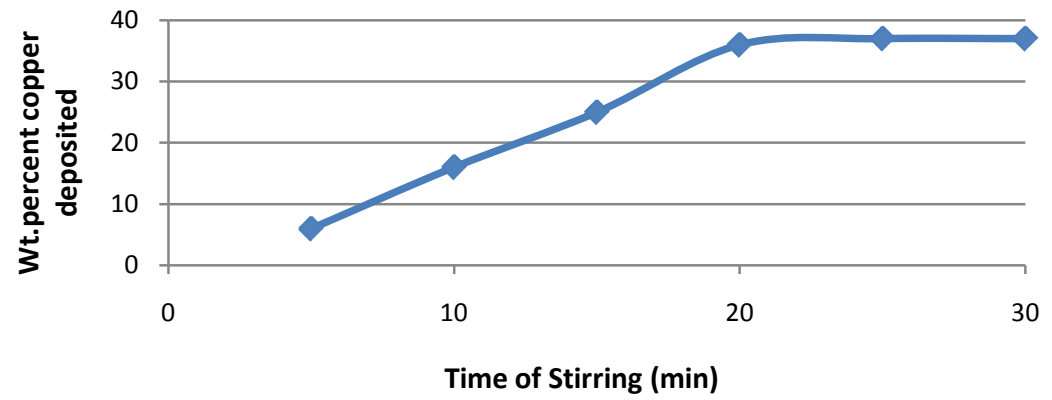

Figure 4. Effect of stirring time on weight percent of copper deposited.

the reaction progress due to depletion of copper. The reaction is generally completed within about 30 min during which time about 35 to $36 \mathrm{wt} \%$ of copper is deposited on the basalt fiber due to depletion copper in the solution and the tendency for precipitation of free copper in the solution instead of a further build up of the coating.

\subsection{Effect of Bath Temperature}

Bath temperature must be kept below $50^{\circ} \mathrm{C}$ because higher temperatures unstabilize the metallization solution. 
At this or higher temperatures dendritic growth of the coating is promoted. Using lower bath temperature uniform thickness can be achieved on the coating [23].

\subsection{Effect of $\mathrm{pH}$}

To obtain any copper deposition, the $\mathrm{pH}$ of the metallization solution must be higher than 12 . For $\mathrm{pH} 12$ or higher the deposition rate increases as the $\mathrm{pH}$ increases, so shorter deposition times are needed to the same thickness. For $\mathrm{pH} 13$, the minimum time needed to get a continuous copper coating is $2 \mathrm{~min}$.

\subsection{Reuse of the Electroless Bath}

In the coating reaction, formaldehyde ( $\mathrm{HCHO})$ reduces $\mathrm{CuSO}_{4}$, and copper deposited on the activated basalt fibers. It was found that after completion of the coating reaction, the $\mathrm{pH}$ of the solution had decreased to 10 . After adding sodium hydroxide in an amount sufficient to maintain $\mathrm{pH}$ at 13 , it was possible to coat copper on the basalt fiber by replenishing the solution with $\mathrm{CuSO}_{4}$ and formaldehyde.

\subsection{Characterization of the Copper Coating}

Figure 5 shows the surface characteristics of uncoated fibers (Figure 5(a)), of copper coated ones (Figure 5(b) and Figure 5(c)) under different metallization conditions, and Figure 5(d) shows the transversal section of copper coated fibres as observed with light microscopy. As it can be seen in the images, the thickness and morphology of the copper layers is highly dependent on the metallization conditions, mainly on sensitization time, activation time, metallization time, bath temperature and $\mathrm{pH}$. Bath temperature must be kept below $50^{\circ} \mathrm{C}$ because higher temperature unstabilizes the metallization solution. At this or higher temperatures dentritic growth of the coating (Figure 5(c)) is promoted. Using lower bath temperatures under the same $\mathrm{pH}$ conditions (pH 13) homogeneous thickness can be achieved on the coatings. To obtain any copper deposition, the $\mathrm{pH}$ of the metallization solution must be higher than 12 . For $\mathrm{pH} 12$ or higher the deposition rate increases as the $\mathrm{pH}$ increases so shorter deposition times are needed to get the same thickness. For $\mathrm{pH} \mathrm{13,} \mathrm{the} \mathrm{minimum} \mathrm{time} \mathrm{needed} \mathrm{to} \mathrm{get} \mathrm{con-}$ tinuous copper coating is 3 mins. After the first stage, the thin copper coating grows homogeneously in thickness with evidence of dentritic growth. The measured thickness of the copper coating for the conditions finally cho$\operatorname{sen}\left(45^{\circ} \mathrm{C}, \mathrm{pH} 13\right.$ and $\left.3 \mathrm{~min}\right)$

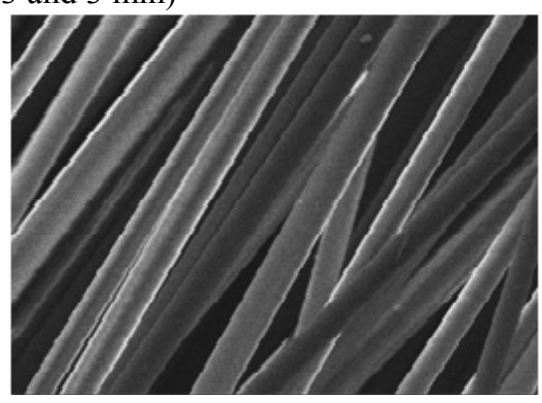

(a)

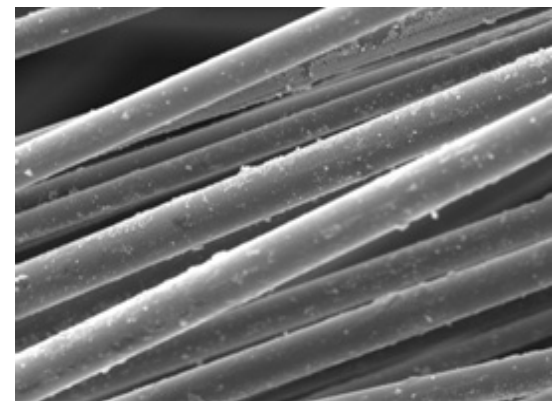

(c)

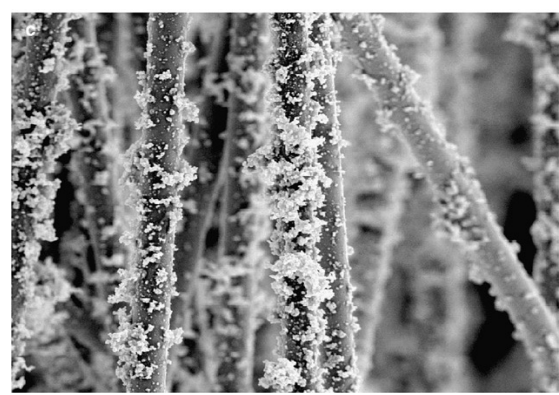

(b)

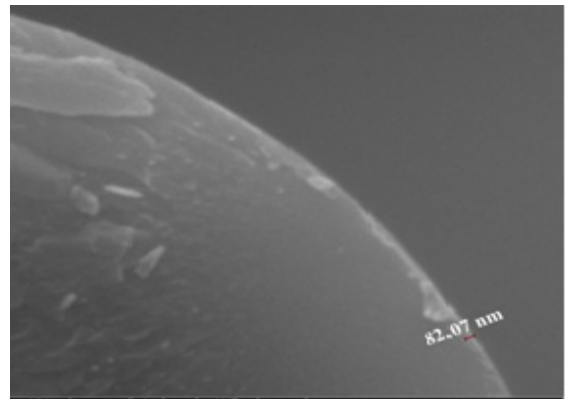

(d)

Figure 5. SEM images of fibers: (a) Uncoated basalt fiber; (b) Copper coated basalt fiber at $50^{\circ} \mathrm{C}, \mathrm{pH} 13$ and $2 \mathrm{~min}$; (c) Copper coated at $40^{\circ} \mathrm{C}, \mathrm{pH} 13$ and $3 \mathrm{~min}$; (d) The thickness of copper coating on basalt fiber. 


\subsection{Fiber Test}

The size of basalt fibers is very short (on the average from 0.5 to $1 \mathrm{~mm}$ ), the key issue of development of the composite is the interaction between the matrix and the fibers. Because of this, the basalt fibers were coated with copper so that development emphasizes the interfacial aspects. In order to evaluate the coating morphology on the fibers, surface of the coated fibers were studied by SEM after the coating process. Evaluation of the effect of copper coating on the strength of the basalt fibers in as-received and after coating was carried out in different thickness of coating as shown in Figure 6. Tensile tests were performed using Single Fiber Test (SFT) method on universal testing machine with special grip (Figure 6(a)) according to ASTM D3379-75. Based on the introduced procedure of the test, a randomly selected basalt fiber was taken from the coated bundle. The gauge length was $25 \mathrm{~mm}$ and the test speed was $2 \mathrm{~mm} / \mathrm{min}$. The elementary fibers retrieved from the roving were stuck to paper windows (Figure 6(b)) and their diameter was measured on an optical microscope. Subsequently, the specimens were clamped to the testing machine, the paper window was cut and the fiber was torn (Figure 6(c)). Hundred tests were carried out for each experiment with an effective gauge length of $10 \mathrm{~mm}$ and a crosshead rate of $1.0 \mathrm{~mm} / \mathrm{min}$.

During the test, fibers were tested and the following values were measured: fiber diameter $\left(\mathrm{d}_{\mathrm{f}}\right)$, fiber cross

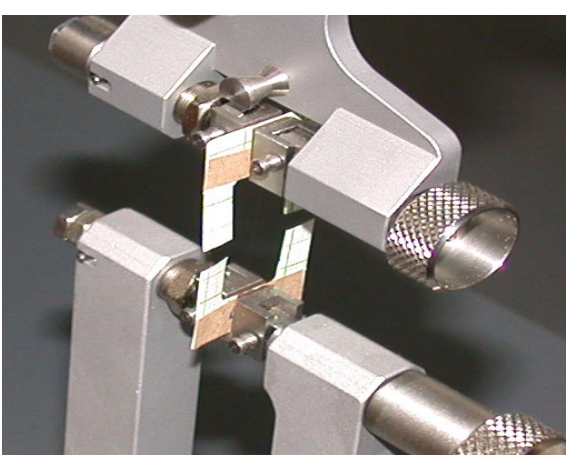

(a)

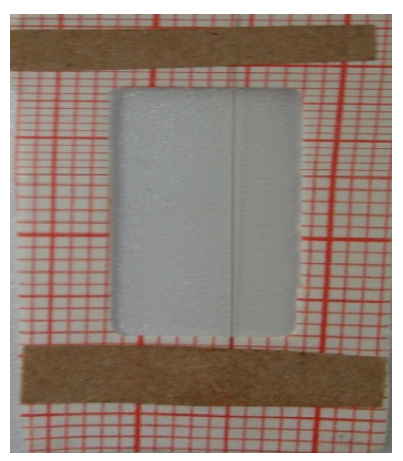

(b)

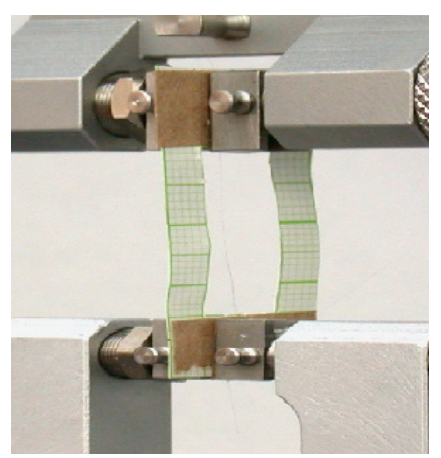

(c)

Figure 6. Tensile test: (a) Special grip universal testing machine; (b) Basalt fiber stuck to paper windows; (c) Tensile test of basalt fibers with $25 \mathrm{~mm}$ gauge length, using paper windows.

Table 3. Results of basalt fiber tensile test.

\begin{tabular}{cccccccc}
\hline & $\begin{array}{c}\text { Fiber diameter } \\
\left(\mathrm{d}_{\mathrm{f}}\right)\end{array}$ & $\begin{array}{c}\text { Cross section } \\
\left(\mathrm{A}_{\mathrm{f}}\right)\end{array}$ & $\begin{array}{c}\text { Maximum force } \\
\left(\mathrm{F}_{\max }\right)\end{array}$ & $\begin{array}{c}\text { Extension at } \\
\text { failure }\left(\Delta_{\max }\right)\end{array}$ & $\begin{array}{c}\text { Specific } \\
\text { elongation }(\varepsilon)\end{array}$ & \multicolumn{2}{c}{ Tensile strength } \\
$\left(\sigma_{\max }\right)$ & $\begin{array}{c}\text { Young } \\
\text { modulus }(\mathrm{E})\end{array}$ \\
\hline Unit & $\mu \mathrm{m}$ & $\mu \mathrm{m}^{2}$ & $\mathrm{~N}$ & $\mathrm{~mm}$ & $\%$ & $\mathrm{MPa}$ \\
Basalt fiber & 15.6 & 190.5 & 0.41 & 1.11 & 4.45 & 2450 \\
\hline
\end{tabular}

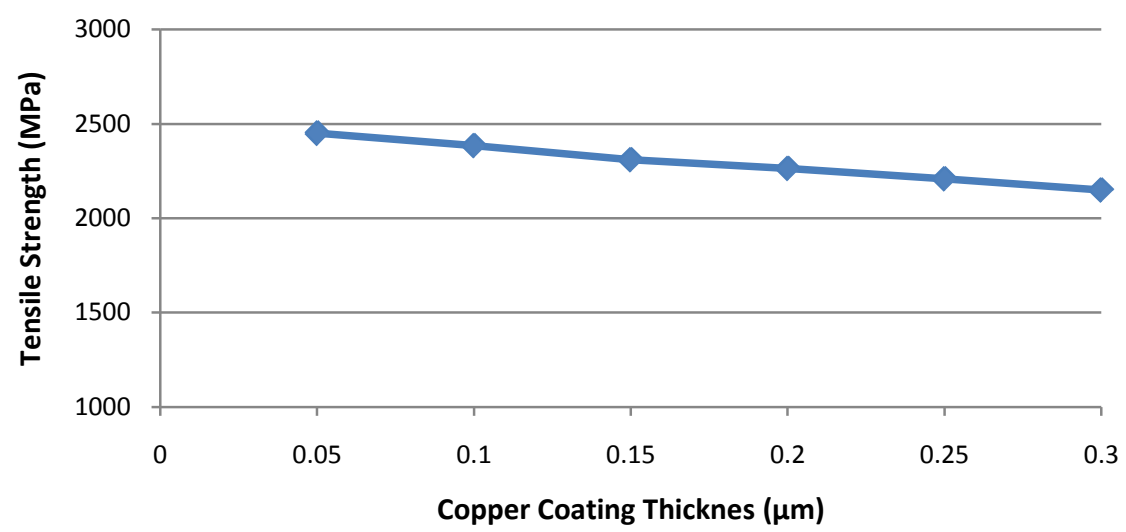

Figure 7. Tensile strength of the copper coated basalt fibers as a function of thickness of copper. 
section area $\left(\mathrm{A}_{\mathrm{f}}\right)$, maximum force $\left(\mathrm{F}_{\max }\right)$, extension at failure $\left(\Delta_{\max }\right)$, specific elongation at failure $(\varepsilon)$, tensile strength $\left(\sigma_{\max }\right)$ and Young modulus (E). The results can be seen in Table 3. The elongation and the Young modulus were calculated from the travel of the testing machine's crosshead. The standard deviations also were calculated for each value.

Figure 7 shows the change of ultimate tensile strength of copper coated basalt fibers as a function of coating thickness. It has been observed from the graph that the tensile strength of copper coated basalt fiber decreases with increase in the coating thickness value. The tensile strength of copper coated basalt fibers has decreased from $2265 \mathrm{MPa}$ in the coating thickness of $0.2 \mu \mathrm{m}$ to $2152 \mathrm{MPa}$ in the coating thickness of $0.3 \mu \mathrm{m}$. The main reason for this decrease in tensile strength of basalt fibers is due to the increment in cross-section of the coated fibers as a result of coating by copper. Copper coated tensile strength is much less than uncoated fibers. This conclusion could be driven from the curve, lowering the tensile strength as a result of increment of coating thickness although with different rates.

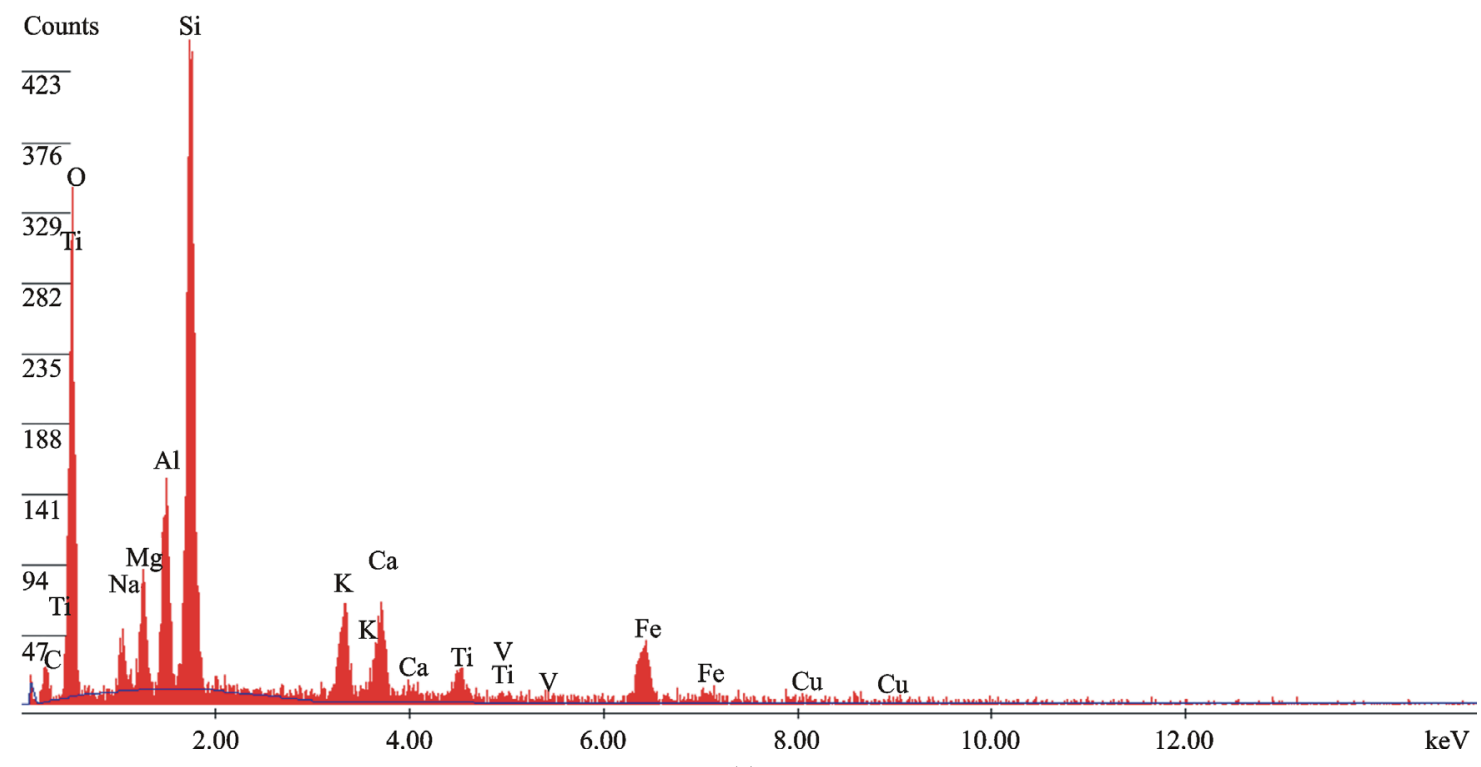

(a)

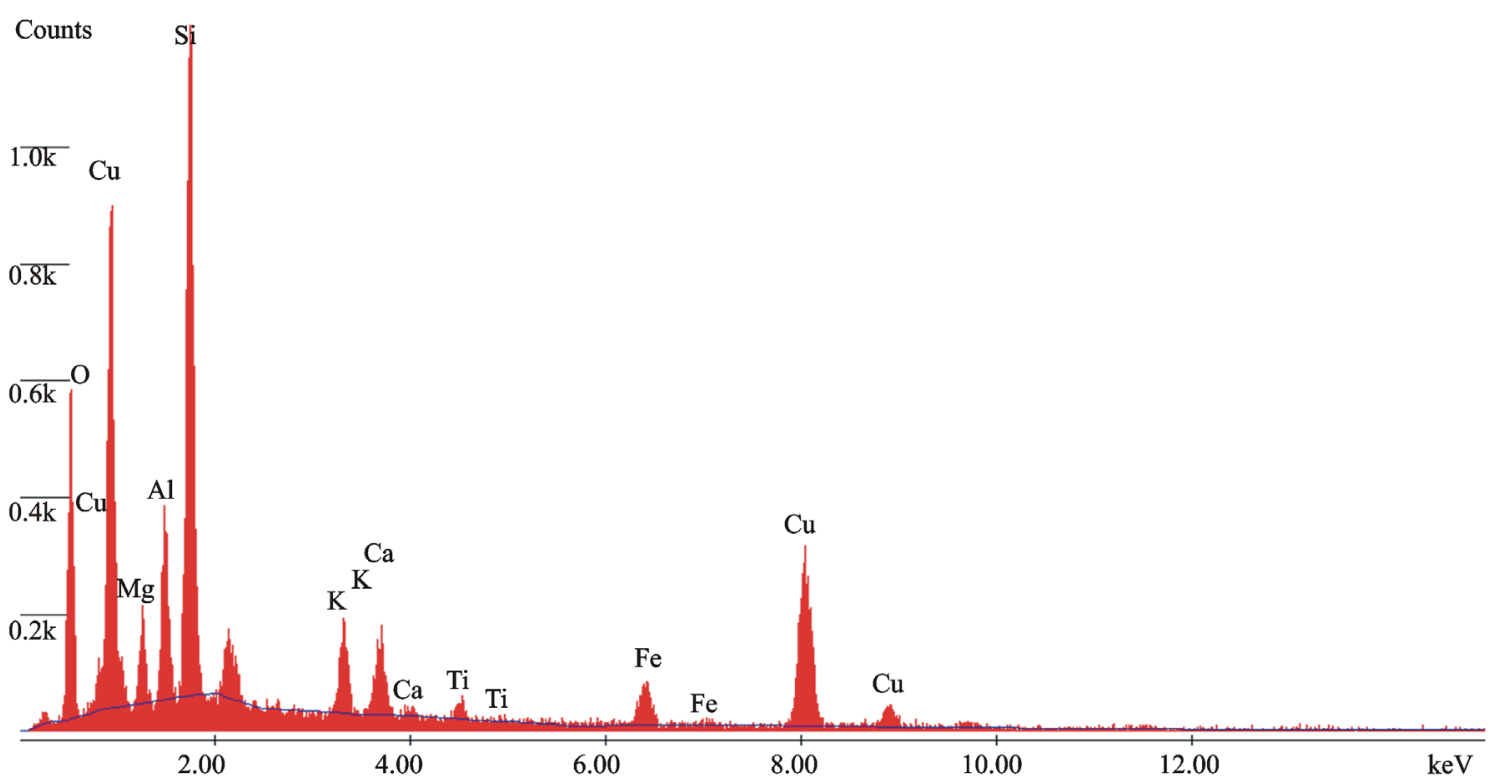

(b)

Figure 8. (a) EDS image of uncoated basalt fiber; (b) EDS image of copper coated basalt fiber. 


\subsection{SEM \& EDS Analysis of Copper Coated Fiber}

The morphology of original basalt fiber and coated basalt fiber was observed using a field emission scanning electron microscope (SEM) measurements were held with a JEOL JSM 6360 - A model with a magnification capacity of $500 \times, 1000 \times, 2000 \times$ and accelerating voltage of $20 \mathrm{KV}$ with working distance (WD) $10 \mathrm{~mm}$ and a spot size 58.Microscopes were equipped with analytical facilities (energy dispersive X-ray spectroscopy-EDS). The aim of the experimental plan is to find the important factors and combinations of Assistance of advanced measurement techniques has been taken to measure coating thickness of fiber at a micro-scale. The experimental results were confirmed by micro-structural studies using scanning electron microscopy (SEM) and energy dispersive spectroscopy (EDS) of short basalt fiber obtained from the chemical test. Through the SEM images, the thickness of copper coating on the basalt fiber was measured. EDS scanning results shows the composition of material which was predominantly copper, from the large Si peaks; it also contains alumina and iron as shown in Figure 8(b). Figure 8(a) and Figure 8(b) show the EDS pattern of uncoated and copper coated basalt fiber respectively. The serious aggregations among the basalt fiber were observed due to the high chemical activity of copper atoms. The original basalt fiber exhibit a glossy surface. After sensitization and activation, the surface becomes dim. The EDS results confirmed the presence of $\mathrm{Cu}$ indicating a successful sensitization and activation process.

\section{Conclusions}

The following conclusions are made from the study:

1) After suitable sensitization and activation treatment, basalt short fibers can be coated with copper sulphate solution by electroless technique.

2) A fairly uniform and continuous coating of copper on basalt fibers can be prepared by electroless technique.

3) Copper coating can improve the wettability of the reinforcement and may prevent the excessive interfacial reaction by enrichment of coated copper on the basalt fiber.

4) Minimum thickness required to form a uniform coating of nickel on surface of basalt fibers is approximately $0.2 \mu \mathrm{m}$. Coating thickness less than $0.2 \mu \mathrm{m}$ can result in the formation of non uniform coating on surface of the fibers, and coating of basalt fibers by copper at higher thickness will result in dendritic growth of coating and nonuniformity on surface of the fibers.

5) The deposition rate can be increased with the increase of bath temperature, $\mathrm{pH}$ and concentration of $\mathrm{PdCl}_{2}$.

6) Copper coating will decrease the tensile strength of the carbon fibers. This decrease is proportional with copper coated layer thickness.

7) If the coating is nonuniform, the chance of stress concentration increases and therefore the strength decreases.

The results of tensile tests of basalt fibers coated with different thickness of copper show that increasing the thickness of coating layer decreases the overall strength of fibers.

\section{References}

[1] Shalu, T., Abhilash, E. and Joseph, M.A. (2009) Development and Characterization of Liquid Carbon Fiber Reinforced Aluminium Matrix Composite. Journal of Materials Processing Technology, 209, 4809-4813. http://dx.doi.org/10.1016/j.jmatprotec.2008.12.012

[2] Bhav Singha, B. and Balasubramanian, M. (2009) Processing and Properties of Copper-Coated Carbon Fibre Reinforced Aluminium Alloy Composites. Journal of Materials Processing Technology, 209, 2104-2110.

[3] Ozturk, S. (2005) The Effect of Fibre Content on the Mechanical Properties of Hemp and Basalt Fibre Reinforced Phenol Formaldehyde Composites. Journal of Materials Science, 40, 4585-4592. http://dx.doi.org/10.1007/s10853-005-1103-z

[4] Aketoma-Basalt Fabrics, Tubes, Prepregs, Rods etc. http://www.laseroptronix.com

[5] Van de Velde, K., Kiekens, P. and Van Langenhove, L. (2006) Basalt Fibers as Reinforcement for Composites.

[6] Militky, J. and Kovacic, V. (1996) Ultimate Mechanical Properties of Basalt Filaments. Textile Research Journal, 66, 225-229. http://dx.doi.org/10.1177/004051759606600407

[7] Cater, S. (2002) Editorial. International Composites News, 40, 559-568. 
[8] Silvain, J.F., Heintz, J.M. and Lahaye, M. (2000) Interface Analysis in Al Alloys/Ni/Carbon Composites. Journal of Materials Science, 35, 961-965. http://dx.doi.org/10.1023/A:1004714911693

[9] Abraham, S., Pai, B.C., Satyanarayana, K.G. and Vaidyan, V.K. (1990) Studies on Nickel Coated Carbon Fibers and Their Composites. Journal of Materials Science, 25, 2839-2845. http://dx.doi.org/10.1007/BF00584890

[10] Judd, N.C.W. (1970) Electroless Deposition of Copper and Nickel on Carbon Fibers. Composites, 1, 345. http://dx.doi.org/10.1016/0010-4361(70)90232-6

[11] Abraham, S., Pai, B.C., Satyanarayana, K.G. and Vaidyan, V.K. (1992) Copper Coating on Carbon Fibres and Their Composites with Aluminium Matrix. Journal of Materials Science, 27, 3479-3486. http://dx.doi.org/10.1007/BF01151823

[12] Warrier, S.G. and Lin, R.Y. (1993) Silver Coating on Carbon and SiC Fibers. Journal of Materials Science, 28, 48684877. http://dx.doi.org/10.1007/BF00361149

[13] Colin, M. (2006) Continuous Fibre Reinforcements for Metal-Matrix Composites. Vol. 21, ASM Handbook, ASM International, Geauga County, 56-58.

[14] Delannay, F., Froyen, L. and Deruyttere, A. (1987) The Wetting of Solids by Molten Metals and Its Relation to the Preparation of Metal-Matrix Composites. Journal of Materials Science, 22, 1-16. http://dx.doi.org/10.1007/BF01160545

[15] Hashim, J., Looney, L. and Hashmi, M.S.J. (2001) The Wettability of SiC Particles by Molten Aluminium Alloy. Journal of Materials Processing Technology, 119, 324-328. http://dx.doi.org/10.1016/S0924-0136(01)00975-X

[16] Urena, A., Rams, J., Escalera, M.D. and Sanchez, M. (2005) Characterization of Interfacial Mechanical Properties in Carbon Fibre/Aluminium Matrix Composites by the Nanoindentation Technique. Composites Science and Technology, 65, 2025-2038. http://dx.doi.org/10.1016/j.compscitech.2005.04.013

[17] Urena, A., Rams, J., Escalera, M.D. and Sanchez, M. (2007) Effect of Copper Electroless Coatings on the Interaction between a Molten Al-Si-Mg Alloy and Coated Short Carbon Fibres. Composites Part A: Applied Science and Manufacturing, 38, 1947-1956. http://dx.doi.org/10.1016/j.compositesa.2007.02.005

[18] Hajjari, E., Divandari, M. and Mirhabibi, A.R. (2004) The Study of Electroless Coating of Nickel on Carbon Fibers. Iranian Journal of Materials Science and Engineering, 1, 43-48.

[19] Hajjari, E. and Divandari, M. (2008) An Investigation on the Microstructure and Tensile Properties of Direct Squeeze Cast and Gravity Die Cast 2024 Wrought Al Alloy. Materials \& Design, 29, 1685-1689. http://dx.doi.org/10.1016/j.matdes.2008.04.012

[20] Aing, W.Y. (1998) Effect of Fiber Coating on the Fabrication of Fiber Reinforced Metal Matrix Composites. Journal of Materials Processing Technology, 73, 78-81. http://dx.doi.org/10.1016/S0924-0136(97)00215-X

[21] Singha, B. and Balasubramanian, M. (2009) Processing and Properties of Copper-Coated Carbon Fibre-Reinforced Aluminium Alloy Composites. Journal of Materials Processing Technology, 209, 2104-2110. http://dx.doi.org/10.1016/j.jmatprotec.2008.05.002

[22] Mishra, S.P. (2005) A Text Book of Fibre Science and Technology. New Age International Private Ltd. Publishers, New Delhi, 312-316.

[23] Abraham, S., Pai, B.C., Satyanarayana, K.G. and Vaidyan, V.K. (1990) Studies on Nickel Coated Carbon Fibres and Their Composites. Journal of Materials Science, 25, 2839-2845. http://dx.doi.org/10.1007/BF00584890 